gas exchange, and leaf diffusive resistance of Glycine $\max$ (L.) Merril cv. Wells II. Plant Physiol. 79:285-289.
Safford, W.E. 1905. The useful plants of the island of Guam. Government Printing Office, Washington D.C.
Todd, G.W., D.L. Chadwick, and Sing-dao Tsai. 1972. Effect of wind on plant respiration. Physiol. Plant. 27:342-346.

\section{A Decision Support System for Apple Thinning in Colorado}

\author{
Matthew K. Rogoyski ${ }^{1}$ \\ Rogers Mesa Research Center, Department of Horticulture, Colorado \\ State University, 3060 Highway 92, Hotchkiss, CO 81419
}

\author{
A. Richard Renquist ${ }^{2}$ \\ Orchard Mesa Research Center, Department of Horticulture, Colorado \\ State University, 3168 B.5 Road, Grand Junction, CO 81503
}

Additional index words. crop load, artificial intelligence, Malus domestica

\begin{abstract}
A decision support system has been developed to help Colorado fruit growers with apple (Malus domestica Borkh.) thinning. This system can also be used as a teaching aid and as a tool for generating research hypotheses. The system determines if fruit thinning is needed by identifying catastrophic events that would eliminate the need for thinning. The major function of this decision support system is determination of tree responsiveness to chemical thinning agents. This is accomplished through analysis of the user's answers to questions related to the physiological status of the trees, environmental data, bearing history, and the apple variety in question. On the basis of the above analysis, two sets of recommendations are presented: general recommendations based on the variety selected, and specific ones for that variety based on growth stage and tree responsiveness to thinners. The user also is provided with the rationale for the recommendations.
\end{abstract}

Western Colorado apple growers are faced with complex decisions regarding crop load management. This intermountain area is prone to spring frosts and heat stress following bloom, with consequent difficulty in predicting the level of fruit set and potential problems with the return bloom. These factors make the decision process unique to this fruit-growing region. The decision support system described here is likely to simplify crop load management, but also may be useful as a teaching aid and hypothesis-generating tool.

There is a wealth of well-documented information about the benefits of apple thinning (Byers and Carbaugh, 1991; Edgerton and Williams, 1981; Looney, 1986; Williams, 1979). Decision support systems are becoming an integral part of the tools available to fruit producers as agriculture changes into an information-intensive endeavor (Crassweller et al., 1989; Plant et al., 1989). Because of the increasing complexity and number of production procedures, marketing questions, and government regulations, de-

Received for publication 23 Sept. 1991. Accepted for publication 20 Apr. 1992. Support by Colorado AFS projects 157 and 138. The cost of publishing this paper was defrayed in part by the payment of page charges. Under postal regulations, this paper therefore must be hereby marked advertisement solely to indicate this fact.

Assistant Professor.

${ }^{2}$ Associate Professor. cision support systems have become helpful tools when dealing with this quantity of information (McKinion and Lemmon, 1985; Naegele et al., 1987; Roach et al., 1987; Schmisseaur and Doluschitz, 1987).

Our decision support system for apple thinning is geared toward students of fruit growing and experienced fruit growers who want to explore or critically evaluate their thinning practices. This decision support system was developed as an "intelligent assistant" to help the users but not to replace experts (Feigenbaum, 1983; Winograd, 1987). The user of our system would be expected to take an active role in the interpretation of the recommendations presented by the system.

The original objective of this work was to develop a teaching aid and hypothesis-generating tool for apple-thinning methods. However, this system is intended to evolve into a management tool for apple growers of western Colorado.

\section{System}

The overall system consists of two programs: 1) the decision support system and 2 ) the program for creating and modifying the knowledge base. The latter program is not needed to use the decision support system. Both programs are written by M.K.R. in the $\mathrm{C}$ language. Their design and implementation are based on concepts and source code examples presented by Harbison and
Steele (1987), Schildt (1987), and Rolston (1988). The source code and related documentation are available upon request. The minimum requirements to run the system are: a computer using MS/PC-DOS (version 2.10 or higher), one floppy disk drive, $256 \mathrm{~K}$ RAM, and a printer.

The knowledge base for the decision support system is organized as a series of modules, implemented as files. Module 1 contains information about events that would eliminate the need for thinning. Module 2 contains the primary knowledge base that consists of factors that affect tree responsiveness to thinners. Module 3 contains a list of growth stages of apple trees pertinent to chemical thinning methods. Module 4 contains names of the varieties to be thinned. Two other groups of modules contain general recommendations and specific recommendations.

The overall flow path of the decisionmaking process and how information in var-

Table 1. Factors that influence tree thinning response.

Spur size

Spur age

Spur position

Shoot length

Condition of the foliage

Tree damage

Intentional trunk/scaffold scoring

Overall limb angle

Tree form

Growth habit

Tree physiological age

Density of flowers

Length of bloom period

Pollinators

Pollinizers

Flower fertilization

History of fruit set

Fruit set previous year

Expected fruit set

Fruit set pattern within cluster

Winter injury to buds

Winter injury to wood

Freeze after thinner application

Occurrence of recent light freeze

Postapplication weather

Weather before application of postbloom thinners

Drying conditions at the time of postbloom thinner use

Rewetting after application of postbloom thinners High temperatures after application of postbloom thinners

Prior application of blossom thinners

Fruit size variation within cluster

Table 2. Catastrophic events that rule-out a need for thinning.

Complete lack of bloom

Major winter injury to the tree

Major fire or herbicidal injury to the tree

Spring frost injury: Nearly all flowers killed throughout tree canopy. 
Table 3. Example from knowledge base: Weather before application of postbloom thinners (one of the factors influencing tree thinning response).

\begin{tabular}{|c|c|c|c|}
\hline \multirow[b]{2}{*}{ Question } & \multicolumn{3}{|c|}{ Answer no. } \\
\hline & 1 & 2 & 3 \\
\hline $\begin{array}{l}\text { Was the weather cloudy } \\
\text { during the week before } \\
\text { application of postbloom } \\
\text { thinners? }\end{array}$ & $\begin{array}{l}\text { Yes, weather was cloudy } \\
\text { for at least } 3 \text { days. } \\
\text { Weighting factor is }-1 \text {. }\end{array}$ & $\begin{array}{l}\text { No, it was sunny } \\
\text { nearly all week. } \\
\text { Weighting factor } \\
\text { is }+1 \text {. }\end{array}$ & $\begin{array}{l}\text { Neither answer is } \\
\text { appropriate. }\end{array}$ \\
\hline
\end{tabular}

ious modules is related is shown in Fig. 1. This information is presented to the user in the form of questions. Each question provides multiple-choice answers, including the nonapplicable option, chosen when none of the answers is appropriate.

\section{Primary knowledge base and the weighting-factor system}

The primary knowledge base (module 2) holds the bulk of qualitative and quantitative information about responsiveness of trees to thinning. The fruit-thinning knowledge base is represented as a set of factors, each with three or more associated attributes. They are designed to establish horticultural, physiological, environmental, and historical data for the trees to be thinned. A list of 31 factors that influence responsiveness of trees to chemical thinning agents is included as a part of the primary knowledge base (Table 1). These factors were selected on the basis of our experience, a list of factors compiled by Edgerton and Williams (1981), and infor-
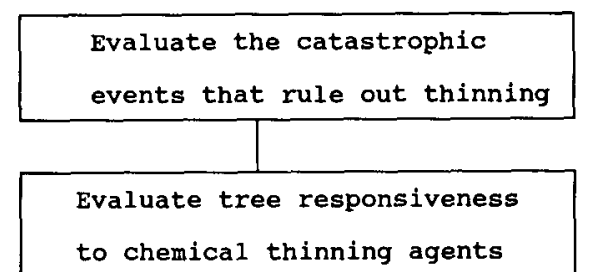

to chemical thinning agents

Determine developmental

stage of fruit to be thinned

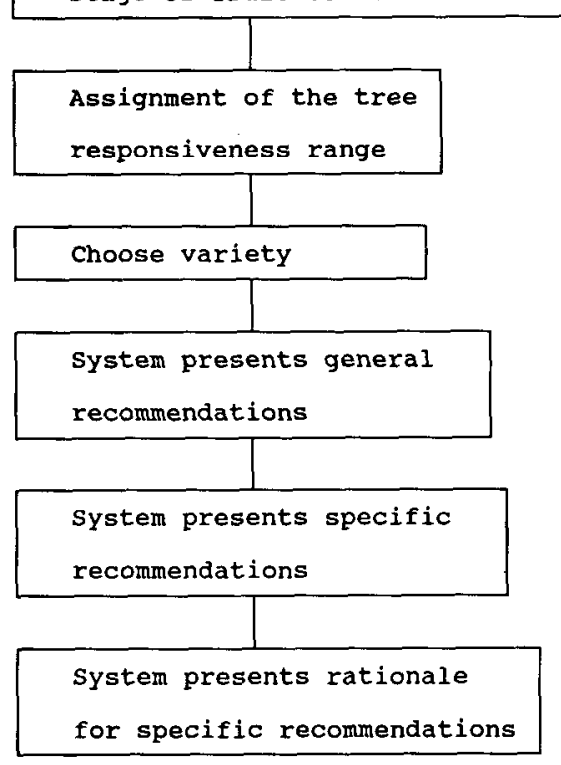

Fig. 1. Overall decision flow path. mation from Byers et al. (1991). The examples of how the user interfaces with various modules is shown in Tables 2, 3, and 4. This text-based interface is in the form of questions with multiple-choice answers.

Each question and answer in the primary knowledge base has a unique weighting factor associated with it. Every factor indicates tree responsiveness to chemical thinning agents, and its value can range from -3 to +3 ( 0 = average responsiveness to chemical thinners; positive values $=$ higher than average concentrations of thinner will be required for optimum crop load; negative values $=$ lower concentration of thinning agent will be necessary).

After the user has responded to these questions, a total weighting factor is calculated by summation of the individual values resulting from the choices made by the user. Then, the lowest and the highest possible sums of applicable weighting factors are obtained from the knowledge base. Questions answered by the user as not appropriate are not included in these calculations. The lowest and highest possible sum of factors for this particular run determines the potential weighting factor range. This range is then divided into three equally spaced intervals. Next, the interval in which the total weighting factor fits is determined; it is this interval that indicates tree responsiveness to thinners.

\section{Recommendations and rationale presented by the system}

After all questions are completely answered, the replies are analyzed, and tree responsiveness to thinners is determined. On the basis of this analysis, two sets of recommendations are presented. General recommendations (not likely to be frequently updated) are based only on the variety selected. The specific recommendations are based on variety, growth stage, and tree responsiveness to thinners. These recommendations contain chemical thinning options, the range of concentrations for appropriate thinners being presented. The recommendations are based on our experience and the Colorado Tree Fruit Pest and Crop Management Guide (Larsen and Cranshaw, 1991). The rationale as to how the system arrived at the answers is presented to the user as the last step.

\section{System overview}

The primary intent during the development of the system was to design a supporting tool for the decisions made by the user. Systems like ours are an aid but not a substitute for the judgment of an experienced fruit grower. The final decision rests in the user's hands.

Evaluation and testing of decision support systems such as ours is a complex endeavor (Werowinski, 1987). One of the difficulties is that the biological events on which thinning is based occur only once a year, and meteorological conditions can be unique to one year. The evaluation of this system was conducted for three consecutive seasons and on the basis of historical information. In most situations, the system assessed trees to be of intermediate responsiveness to thinners, as

Table 4. Sequence of thinning agent choices related to overall thinning strategy. (The requirement for minimum fruit size overrides the requirement for the minimum number of days after full bloom.)

\begin{tabular}{ll}
\hline Choice & Thinning strategy \\
\hline 1 & Full bloom ( $80 \%$ to $90 \%$ flowers opened) \\
Thinning agent: Wilthin (carbamide) \\
Early postbloom \\
Largest fruit diam: $3 \mathrm{~mm}$ \\
Days from full bloom: 7 to 14 \\
This category is for all varieties except Delicious. \\
Thinning agent: Amid-Thin (NAD or naphthaleneacetamide) \\
Postbloom option A \\
Largest fruit diam: 10 to 15 mm \\
Days from full bloom: 15 to 25 \\
Anticipated temp: $10 \mathrm{C}$ or above within 5 days of application \\
Thinning agent: NAA (naphthaleneacetic acid) \\
Postbloom option B \\
Largest fruit diam: 10 to 15 mm (some thinning will be achieved \\
even with fruit diameters of 15 to 25 mm) \\
Days from full bloom: 10 to 25 \\
Anticipated temp: 21 to $32 \mathrm{C}$ within 5 days of application. (Select \\
choice no. 3 if temperature is outside this range) \\
Thinning agent: Sevin (carbaryl)
\end{tabular}


the factors that increase responsiveness are often independent of, and tend to be offset by, the opposing factors.

There are several ways to use information generated by the system: 1) as a teaching aid; 2) as a production tool following completion of extensive testing and validation of system performance; 3) as a means of generating hypotheses for crop load management investigations.

The decision support system has been found to be most useful as an aid in systematic, review of tree responsiveness to thinners during a variety of hypothetical conditions. By systematically altering the information about prevailing conditions, the user can examine the effect that various conditions have on tree responsiveness.

The power of decision support systems resides in their associated knowledge bases (Feigenbaum, 1983). When using the system presented here, it is intended that the user expands and regularly updates the knowledge base, including the weighting factor system, to provide a more robust system. This editing and updating can be accomplished with the program used to create the knowledge base. As this system evolves, it is intended to help growers arrive at the best possible solutions to their crop load management problems through systematic examination of factors affecting thinning response.

\section{Literature Cited}

Byers, R.E. and D.H. Carbaugh. 1991. Effect of chemical thinning sprays on apple fruit set. HortTechnology 1:41-48.

Byers, R.E., D.H. Carbaugh, C.N. Presley, and T.K. Wolf. 1991. The influence of low light on apple fruit abscission. J. Hort. Sci. 66:7-17.

Crassweller, R.M., P.H. Heinemann, and E.G. Rajotte. 1989. An expert system on a microcomputer for determining apple tree spacing. HortScience 24:148.

Edgerton, L.J. and M.W. Williams. 1981. Fruit thinning of apples and pears with chemicals. U.S. Dept. Agriculture, Agr. Info. Bul. 289.

Feigenbaum, E.A. 1983. Knowledge engineering: The aunlied side. D. 37-55. In: J.E. Hayes and D. Michie (eds.). Intelligent system: The unprecedented opportunity. Ellis Howard, Chichester, U.K.

Harbison, S.P. and G.L. Steele. 1987. C: A Reference manual. 2nd ed. Prentice-Hall, Englewood Cliffs, N.J.

Larsen, H.L. and W.S. Cranshaw. 1991. Colorado tree fruits: 1991 Pest and crop management guide. Colorado State Univ. Coop. Ext. Bul. XCM-41.
Looney, N.E. 1986. Chemical thinning of apple: Some new strategies and important refinements to old procedures. Acta Hort. 179:597-604.

McKinion, J.M. and H.L. Lemmon. 1985. Expert systems for agriculture. Computers \& Electronics in Agr. 1:31-40.

Naegele, J.A., W.O. Rasmussen, and J.K. Eisler. 1987. The emergence of expert decision support systems in agriculture. J. Comp. Appl. 2(1):3642.

Plant, R.E., F.G. Zalom, J.A. Young, and R.E. Rice. 1989. CALEX/Peaches, an expert system for the diagnosis of peach and nectarine disorders. HortScience 24:700.

Roach, J., R. Vikar, C. Drake, and M. Weaver. 1987. An expert system for helping apple growers. Computers \& Electronics in Agr. 297-108.

Ralston, D.W. 1988. Principles of artificial intelligence and expert systems development. McGraw-Hill, New York.

Schildt, H. 1987. C: The complete reference. Osborne McGraw-Hill, Berkley, Calif.

Schmisseaur, R. and R. Doluschitz. 1987. Expert system insights: The discipline and agricultural developments. J. Computer Appl. 2(21):20-25.

Werowinski, C.R. 1987: Documenting rules improves ES maintenance. Applied Artifical Intelligence Rpt. 4:16-17.

Williams, M.W. 1979. Chemical thinning of apples. Hort. Rev. 1:270-300.

Winograd, T. 1987. Brainwaves. Al Expert 2(21):80. 